DIW BERLIN

Discussion

Papers

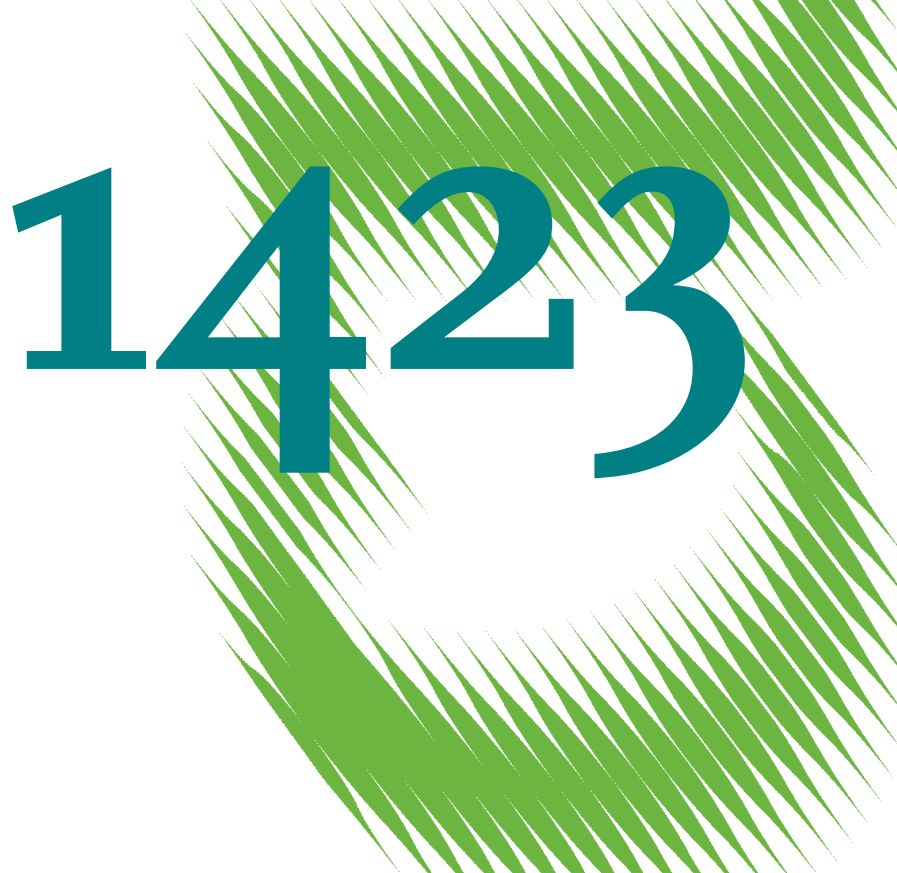

Short-Term Price Overreaction: Identification, Testing, Exploitation 
Opinions expressed in this paper are those of the author(s) and do not necessarily reflect views of the institute.

IMPRESSUM

(C) DIW Berlin, 2014

DIW Berlin

German Institute for Economic Research

Mohrenstr. 58

10117 Berlin

Tel. +49 (30) $89789-0$

Fax +49 (30) $89789-200$

http://www.diw.de

ISSN electronic edition 1619-4535

Papers can be downloaded free of charge from the DIW Berlin website:

http://www.diw.de/discussionpapers

Discussion Papers of DIW Berlin are indexed in RePEc and SSRN:

http://ideas.repec.org/s/diw/diwwpp.html

http://www.ssrn.com/link/DIW-Berlin-German-Inst-Econ-Res.html 


\title{
Short-Term Price Overreactions: Identification, Testing, Exploitation
}

\author{
Guglielmo Maria Caporale* \\ Brunel University, London, CESifo and DIW Berlin \\ Luis Gil-Alana \\ University of Navarra \\ Alex Plastun \\ Ukrainian Academy of Banking
}

October 2014

\begin{abstract}
This paper examines short-term price reactions after one-day abnormal price changes and whether they create exploitable profit opportunities in various financial markets. A t-test confirms the presence of overreactions and also suggests that there is an "inertia anomaly", i.e. after an overreaction day prices tend to move in the same direction for some time. A trading robot approach is then used to test two trading strategies aimed at exploiting the detected anomalies to make abnormal profits. The results suggest that a strategy based on counter-movements after overreactions does not generate profits in the FOREX and the commodity markets, but it is profitable in the case of the US stock market. By contrast, a strategy exploiting the "inertia anomaly" produces profits in the case of the FOREX and the commodity markets, but not in the case of the US stock market.
\end{abstract}

Keywords: Efficient Market Hypothesis, anomaly, overreaction hypothesis, abnormal returns, contrarian strategy, trading strategy, trading robot, t-test

JEL classification: G12, G17, C63

Corresponding author: Professor Guglielmo Maria Caporale, Research Professor at DIW Berlin. Department of Economics and Finance, Brunel University, London, UB8 3PH, UK. Tel.: +44 (0)1895 266713. Fax: +44 (0)1895 269770. Email: GuglielmoMaria.Caporale@brunel.ac.uk 


\section{Introduction}

The Efficient Market Hypothesis (EMH) is one of the cornerstones of financial economics (Fama, 1965). Its implication is that there should not be any exploitable profit opportunities in financial markets. However, the empirical literature has documented the presence of a number of so-called "market anomalies”, i.e. price behaviour that appears to create abnormal profit opportunities.

One of the most famous stock market anomalies is the so-called overreaction hypothesis detected by De Bondt and Thaler (1985), who showed that investors tend to give excessive weight to recent relative to past information when making their portfolio choices. A special case of the overreaction hypothesis is short-term price reactions after one-day abnormal price changes. Empirical studies on various financial markets show that after such price changes there are bigger contrarian price movements than after normal (typical) daily fluctuations (Atkins and Dyl, 1990; Bremer and Sweeney, 1991; Bremer, Hiraki and Sweeney, 1997; Cox and Peterson, 1994; Choi and Jayaraman, 2009; etc).

This paper provides new evidence on the overreaction anomaly by analysing both price counter-movements and movements in the direction of the overreaction and comparing them to those after normal days. First, we carry out t-tests to establish whether the data generation process of prices is the same after days of overreaction and typical days. We show that short-term overreactions cause the emergence of patterns in price behaviour, i.e. temporary market inefficiencies that could result in extra profit opportunities. Then we use a trading robot method to examine whether or not trading strategies based on the detected statistical anomalies are profitable, i.e. whether price overreactions are simply statistical phenomena or can also be seen as evidence against the EMH. The analysis is carried out for various financial markets: the US stock market (the Dow Jones Index and two companies 
included in this index), FOREX (EURUSD, USDJPY, GBPCHF, AUDUSD) and commodity markets (Gold, Oil).

The remainder of this paper is organised as follows. Section 2 briefly reviews the existing literature on the overreaction hypothesis. Section 3 outlines the methodology followed in this study. Section 4 discusses the empirical results. Section 5 offers some concluding remarks.

\section{Literature review}

There is a vast empirical literature on the EMH. Kothari and Warner (2006) reviewed over 500 studies providing evidence in support of this paradigm. However, as pointed out by Ball (2009), there is also plenty of evidence suggesting the presence of market anomalies apparently inconsistent with EMH such as over- and under-reactions to information flows, volatility explosions and seasonal yield bursts, yield dependence on different variables such as market capitalisation, dividend rate, and market factors, etc. Over- or under-reactions are significant deviations of asset prices from their average values during certain periods of time (Stefanescu et al., 2012).

The overreaction hypothesis was first considered by De Bondt and Thaler (DT, 1985), following the work of Kahneman and Tversky (1982), who had shown that investors overvalue recent relative to past information. The main conclusions of DT were that the best (worst) performing portfolios in the NYSE over a three-year period tended to under (over)perform over the following three-year period. Overreactions are associated with irrational behaviour of investors who overreact to news arrivals. This leads to significant deviations of asset prices from their fundamental value. Such overreactions normally lead to price corrections. An interesting fact, mentioned by DT, is an asymmetry in the overreaction: its size is bigger for undervalued than for overvalued stocks. DT also reported the existence of a "January effect", i.e. overreactions tend to occur mostly in that month. 
Subsequent studies on the overreaction hypothesis include Brown, Harlow and Tinic (1988), who analysed NYSE data for the period 1946-1983 and reached similar conclusions to DT; Zarowin (1989), who showed the presence of short-term market overreactions; Atkins and Dyl (1990), who found overreactions in the NYSE after significant price changes in one trading day, especially in the case of falling prices; Ferri and Min (1996), who confirmed the presence of overreactions using S\&P 500 data for the period 1962-1991; Larson and Madura (2003), who used NYSE data for the period 1988-1998 and also showed the presence of overreactions, as did Clements et al. (2009).

Overreactions have also been found in other stock markets, including Spain (Alonso and Rubio, 1990), Canada (Kryzanowsky and Zhang, 1992), Australia (Brailsford, 1992; Clare and Thomas, 1995), Japan (Chang et al., 1995), Hong-Kong (Akhigbe et al., 1998), Brazil (DaCosta and Newton, 1994), Richards, 1997), New Zealand (Bowman and Iverson, 1998)), China (Wang et al., 2004)), Greek (Antoniou et. al., 2005), Turkey (Vardar and Okan, 2008) and Ukraine (Mynhardt and Plastun, 2013). Some evidence is also available for other types of markets, such as the gold market (Cutler, Poterba, and Summers, 1991) and the option market (Poteshman, 2001).

A few studies have examined whether such anomalies give rise to profit opportunities. In particular, Jegadeesh and Titman (1993) developed a trading strategy based on an algorithm consisting in undertaking transactions in the opposite direction to the previous movement at a monthly frequency. They found that such a strategy generates a $12 \%$ profit per year. A similar strategy, but at a weekly frequency, was developed by Lehmann (1990), and was found to be equally profitable.

\section{Data and methodology}

We analyse the following daily series: for the US stock market, the Dow Jones index and stocks of two companies included in this index (Microsoft and Boeing - for the trading robot 
analysis we also add Wal Mart and Exxon); for the FOREX, EURUSD, USDJPY and GBCHF (for the trading robot analysis also AUDUSD); for commodities, Gold and Oil (only Gold for the trading robot analysis owing to data unavailability). The sample period covers the period from January 2002 till the end of September 2014 (for the trading robot analysis the period is 2012-2014).

\subsection{Student's t-tests}

First we carry out Student's t-tests to confirm (reject) the presence of stock market anomalies after overreactions, then we apply the trading robot approach to establish whether they create exploitable profit opportunities. According to the classical overreaction hypothesis, an overreaction should be followed by a correction, i.e. price countermovements, and bigger than after normal days. If one day is not enough for the market to incorporate new information, i.e. to overreact, then after one-day abnormal price changes one can expect movements in the direction of the overreaction bigger than after normal days.

Therefore the following two hypotheses will be tested:

H1: Counter-reactions after overreactions differ from those after normal days.

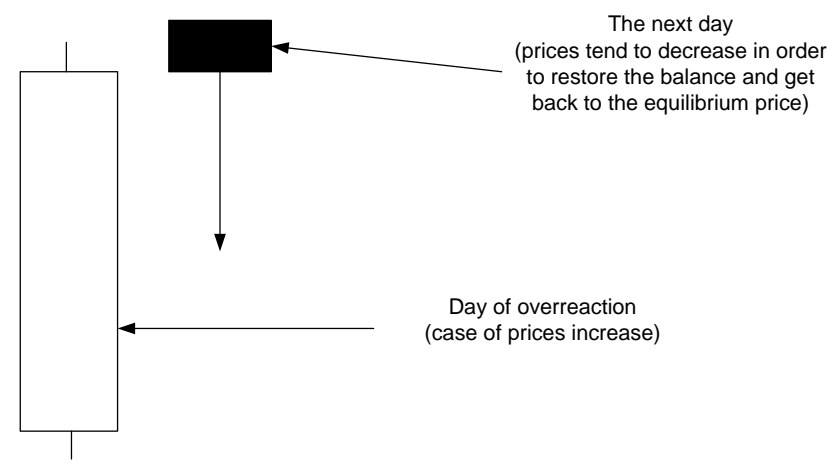


H2: Price movements after overreactions in the direction of the overreaction differ from such movements after normal days.

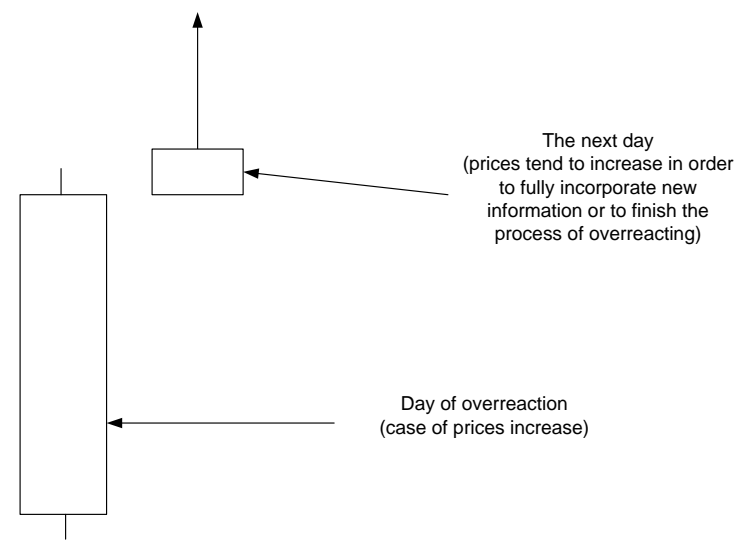

The null hypothesis is in both cases that the data after normal and overreaction days belong to the same population.

Our dataset is quite large, and therefore on the basis of the Central Limit Theorem (see Mendenhall, Beaver and Beaver, 2003) it can be argued that normality holds as required for carrying out t-tests. As a further check for normality, in the case of the EURUSD we also apply Pearson's criterion: we randomly select 100 consecutive price ranges for the period 2006-2008 (Table 1) and calculate the critical values of the distribution. Since they do not exceed those of the chi-square distribution, one can conclude that the data are normally distributed and it is legitimate to perform Student's t-tests.

Table 1: "Normality" test for the EUR/USD data

\begin{tabular}{|l|c|c|c|}
\hline & 2006 & 2007 & 2008 \\
\hline Observations & \multicolumn{3}{|c|}{100} \\
\hline Average & 80.14 & 73.62 & 145.19 \\
\hline Standard deviation & 28.37 & 24.5 & 51.67 \\
\hline Confidence level & \multicolumn{3}{|c|}{0.95} \\
\hline Chi-square values & 6.1 & 9.37 & 9.12 \\
\hline $\begin{array}{l}\text { Chi-square distribution critical value (hi(p=0.95, } \\
\mathrm{f}=7) \text { ) }\end{array}$ & \multicolumn{3}{|c|}{ Data are normally distributed } \\
\hline Conclusion & \multicolumn{3}{|c|}{} \\
\hline
\end{tabular}

We analyse short-term overreactions, so the period of analysis is 1 day (one trading session). The parameters characterising price behaviour over such a time interval are maximum, minimum, open and close prices. In most studies price movements are measured 
as the difference between the open and close price. In our opinion the daily return, i.e. the difference between the maximum and minimum prices during the day, is more appropriate. This is calculated as:

$$
R_{i}=\frac{\left(\operatorname{High}_{i}-\operatorname{Low}_{i}\right)}{\operatorname{Low}_{i}} \times 100 \%
$$

where $R_{i}$ is the \% daily return, $\mathrm{High}_{i}$ is the maximum price, and $\operatorname{Low}_{i}$ is the minimum price for day $i$.

We consider three definitions of “overreaction”:

1) when the current daily return exceeds the average plus one standard deviation

$$
R_{i}>\left(\bar{R}_{n}+\delta_{n}\right)
$$

where $\bar{R}_{n}$ is the average size of daily returns for period $n$

$$
\bar{R}_{n}=\sum_{i=1}^{n} R_{i} / n
$$

and $\delta_{n}$ is the standard deviation of daily returns for period $n$

$$
\delta_{n}=\sqrt{\frac{1}{n} \sum_{i=1}^{n}\left(R_{i}-\bar{R}\right)^{2}}
$$

2) when the current daily return exceeds the average plus two standard deviations, i.e.,

$$
R_{i}>\left(\bar{R}_{n}+2 \times \delta_{n}\right)
$$

3) when the current daily return exceeds the average plus three standard deviations, i.e.,

$$
R_{i}>\left(\bar{R}_{n}+3 \times \delta_{n}\right)
$$

The next step is to determine the size of the price movement during the next day. For Hypothesis 1 (the counter-reaction or counter-movement assumption), we measure it as the 
difference between the next day's open price and the maximum deviation from it in the opposite direction to the price movement in the overreaction day.

If the price increased, then the size of the counter-reaction is calculated as:

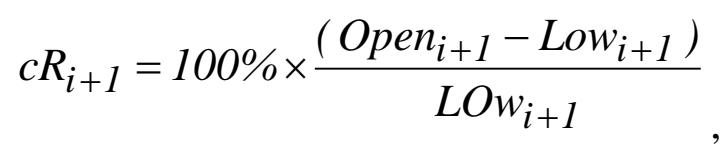

where $c R_{i+1}$ is the counter-reaction size, and Open $_{i+l}$ is the next day's open price.

If the price decreased, then the corresponding definition is:

$$
c R_{i+1}=100 \% \times \frac{\left(\text { High }_{i+1}-\text { Open }_{i+1}\right)}{\text { Open }_{i+1}} .
$$

In the case of Hypothesis 2 (movement in the direction of the overreaction), either equation (8) or (7) is used depending on whether the price has increased or decreased.

Two data sets (with $c R_{i+1}$ values) are then constructed, including the size of price movements after normal and abnormal price changes respectively. The first data set consists of $c R_{i+1}$ values after one-day abnormal price changes. The second contains $c R_{i+1}$ values after a day with normal price changes. The null hypothesis to be tested is that they are both drawn from the same population.

\subsection{Trading robot analysis}

The trading robot approach considers the short-term overreactions from a trader's viewpoint, i.e. whether it is possible to make abnormal profits by exploiting the overreaction anomaly. The trading robot simulates the actions of a trader according to an algorithm (trading strategy). This is a programme in the MetaTrader terminal that has been developed in MetaQuotes Language 4 (MQL4) and used for the automation of analytical and trading processes. Trading robots (called experts in MetaTrader ) allow to analyse price data and manage trading activities on the basis of the signals received. 
MetaQuotes Language 4 is the language for programming trade strategies built in the client terminal. The syntax of MQL4 is quite similar to that of the C language. It allows to programme trading robots that automate trade processes and is ideally suited to the implementation of trading strategies. The terminal also allows to check the efficiency of trading robots using historical data. These are saved in the MetaTrader terminal as bars and represent records appearing as TOHLCV (HST format). The trading terminal allows to test experts by various methods. By selecting smaller periods it is possible to see price fluctuations within bars, i.e., price changes will be reproduced more precisely. For example, when an expert is tested on one-hour data, price changes for a bar can be modelled using one-minute data. The price history stored in the client terminal includes only Bid prices. In order to model Ask prices, the strategy tester uses the current spread at the beginning of testing. However, a user can set a custom spread for testing in the "Spread", thereby approximating better actual price movements.

We examine two trading strategies:

- Strategy 1 (based on H1): This is based on the classical short-term overreaction anomaly, i.e. the presence the abnormal counter-reactions the day after the overreaction day. The algorithm is constructed as follows: at the end of the overreaction day financial assets are sold or bought depending on whether abnormal price increases or decreased respectively have occurred. An open position is closed if a target profit value is reached or at the end of the following day (for details of how the target profit value is defined see below).

- $\quad$ Strategy 2 (based on H2): This is based on the non-classical short-term overreaction anomaly, i.e. the presence the abnormal price movements in the direction of the overreaction the following day. The algorithm is built as follows: at the end of the overreaction day financial assets are bought or sold depending on whether abnormal 
price increases or decreases respectively have occurred. Again, an open position is closed if a target profit value is reached or at the end of the following day.

In order to avoid data-snooping bias and artificial fitting of certain parameters ${ }^{1}$ we adopt the following testing procedure.

1. We use a base period (data from 2013) to obtain the optimal parameters for the behaviour of asset prices (an example of such optimisation is reported in Appendix A).

2. We test the trading strategy with the optimal parameters on the base period (2013 data) and two independent (non-optimised) periods (2012 and 2014) to see whether it is profitable (an example can be found in Appendix B).

3. We perform continuous testing for the period 2012-2014 to obtain average results for the trading strategy.

4. The results of continuous trading are used to assess the effectiveness of the strategy. If total profits from trading are $>0$ and the number of profitable trades is $>50 \%$, and the results are rather stable for different periods, then we conclude that there is a market anomaly and it is exploitable.

The results of the trading strategy testing and some key data are presented in the "Report" in Appendix B. The most important indicators given in the "Report" are:

- Total net profit: this is the difference between "Gross profit" and "Gross loss" measured in US dollars. We used marginal trading with the leverage 1:100, therefore it is necessary to invest $\$ 1000$ to make the profit mentioned in the Trading Report. The annual return is defined as Total net profit/100, so, for instance, an annual total net profit of $\$ 100$ represents a $10 \% a n n u a l$ return on the investment;

- Profit trades: \% of successful trades in total trades;

\footnotetext{
${ }^{1}$ By changing the values of various parameters of the trading strategy one can make it profitable, but this would work only for the specific data set being used, not in general.
} 
- Expected payoff: the mathematical expectation of a win. This parameter represents the average profit/loss per trade. It is also the expected profitability/unprofitability of the next trade;

- Total trades: total amount of trade positions;

- Bars in test: the number of past observations modelled in bars during testing.

The results are summarised in the "Graph" section of the "Report": this represents the account balance and general account status considering open positions. The "Report" also provides full information on all the simulated transactions and their financial results. The following parameters affect the profitability of the trading strategies (the next section explains how they are set):

- Criterion for overreaction (symbol: sigma_dz): the number of standard deviations added to the mean to form the standard day interval;

- Period of averaging (period_dz): the size of data set on which base mean and standard deviation are counted;

- $\quad$ Time in position (time_val): how long (in hours) the opened position has to be held;

- Expected profit per trade or Take Profit (profit_koef): the size of profit expected to result from a trade, measured as:

Take Profit=profit_koef*sigma_dz;

- Maximum amount of losses per trade or Stop Loss (stop): the size of losses the trader is willing to incur in a trade, defined as follows:

$$
\text { Stop Loss =stop*sigma_dz. }
$$

\section{Empirical results}

The first step is to set the basic overreaction parameters/criterions by choosing the number of standard deviations (sigma_dz) to be added to the average to form the "standard" day 
interval for price fluctuations and the averaging period to calculate the mean and the standard deviation(symbol: period_dz).

For this purpose we used the Dow Jones Index data for the period 1987-2012. The number of abnormal returns detected in the period 1987-2012 is reported in Table 2.

Table 2: Number of abnormal returns detections in Dow-Jones index during 1987-2012

\begin{tabular}{|l|c|c|c|c|c|c|c|c|}
\hline \multicolumn{1}{|c|}{ Period_dz } & \multicolumn{2}{c|}{5} & \multicolumn{2}{c|}{10} & \multicolumn{2}{c|}{20} & \multicolumn{2}{c|}{30} \\
\hline Indicator & Number & $\%$ & Number & $\%$ & Number & $\%$ & Number & $\%$ \\
\hline Overall & 6458 & 100 & 6454 & 100 & 6444 & 100 & 6434 & 100 \\
\hline $\begin{array}{l}\text { Number of abnormal returns } \\
\text { (criterion =mean+sigma_dz) }\end{array}$ & 1297 & 20 & 1183 & 18 & 1123 & 17 & 1070 & 17 \\
\hline $\begin{array}{l}\text { Number of abnormal returns } \\
\text { (criterion= mean+2*sigma_dz) }\end{array}$ & 587 & 9 & 474 & 7 & 379 & 6 & 371 & 6 \\
\hline $\begin{array}{l}\text { Number of abnormal returns } \\
\text { (criterion = mean+3*sigma_dz) }\end{array}$ & 290 & 4 & 194 & 3 & 159 & 2 & 145 & 2 \\
\hline
\end{tabular}

As can be seen, both parameters (averaging period and number of standard

deviations added to the mean) affect the number of detected anomalies. Changes in the averaging period only have a small effect (the difference between the results when the period considered is 5 and 30 respectively is less than 10\%). By contrast, each additional standard deviation significantly decreases the number of observed abnormal returns (by $50 \%$ for each additional sigma). Therefore $2-4 \%$ of the full sample (the number of abnormal returns in the case of 3 sigmas) is not sufficiently representative to draw conclusions. That is why we set the parameter sigma_dz equal to 1 . To make sure that this choice is reasonable in practice we test the trading strategy based on overreactions with a different set of parameters (see Appendix C). The results provide evidence in favour of 1 as an appropriate value for the sigma_dz parameter. Student's t -tests of short-term counter-reactions carried out for the Dow Jones index over the period 1987-2012 (see Table 3) suggest that the optimal averaging periods are 20 and 30 (the corresponding t-statistics are significantly higher than for other averaging periods), and thus the t-tests are also performed for these. 
Table 3: T-test of the short-term counter-reactions after the day of the overreaction for the Dow-Jones index during 1987-2012

\begin{tabular}{|l|r|r|r|r|r|r|r|r|}
\hline Period_dz & \multicolumn{2}{|c|}{5} & \multicolumn{2}{|c|}{10} & \multicolumn{2}{|c|}{20} & \multicolumn{2}{c|}{30} \\
\hline & abnormal & normal & abnormal & Normal & abnormal & normal & abnormal & normal \\
\hline Number of matches & 1297 & 5161 & 1183 & 5271 & 1123 & 5321 & 1070 & 5364 \\
\hline Mean & $0,97 \%$ & $0,95 \%$ & $1,00 \%$ & $0,94 \%$ & $1,06 \%$ & $0,93 \%$ & $1,09 \%$ & $0,92 \%$ \\
\hline Standard deviation & $0,97 \%$ & $0,80 \%$ & $1,01 \%$ & $0,80 \%$ & $1,08 \%$ & $0,78 \%$ & $1,12 \%$ & $0,77 \%$ \\
\hline t-criterion & 0,859571855 & 2,033267584 & 4,230763317 & 4,722439164 \\
\hline t-critical (p=0.95) & \multicolumn{8}{|c|}{1,96} \\
\hline Null hypothesis & \multicolumn{1}{|c|}{ accepted } & \multicolumn{2}{|c|}{ rejected } & rejected & \multicolumn{2}{|c|}{ rejected } \\
\hline
\end{tabular}

The results for $\mathrm{H} 1$ are presented in Tables 4 - 8. In the case of the commodity markets (see Table 4) H1 is rejected for Oil (this evidence in favor of anomaly presence) but cannot be rejected for Gold for both averaging periods.

Table 4: T-test of Hypothesis 1 - case of commodity markets

\begin{tabular}{|c|c|c|c|c|c|c|c|c|}
\hline $\begin{array}{l}\text { Period of averaging } \\
\text { (period } \mathrm{dz} \text { ) }\end{array}$ & \multicolumn{4}{|c|}{20} & \multicolumn{4}{|c|}{30} \\
\hline Type of asset & \multicolumn{2}{|c|}{ Gold } & \multicolumn{2}{|c|}{ Oil } & \multicolumn{2}{|c|}{ Gold } & \multicolumn{2}{|c|}{ Oil } \\
\hline Indicator & abnormal & normal & abnormal & normal & abnormal & normal & abnormal & normal \\
\hline Number of matches & 536 & 2637 & 536 & 2637 & 538 & 2763 & 496 & 2667 \\
\hline Mean & $0.84 \%$ & $0.80 \%$ & $0.84 \%$ & $0.80 \%$ & $0.83 \%$ & $0.79 \%$ & $1.73 \%$ & $1.38 \%$ \\
\hline Standard deviation & $0.73 \%$ & $0.77 \%$ & $0.73 \%$ & $0.77 \%$ & $0.75 \%$ & $0.76 \%$ & $1.56 \%$ & $1.31 \%$ \\
\hline t-criterion & \multicolumn{2}{|c|}{1.4} & \multicolumn{2}{|c|}{4.03} & \multicolumn{2}{|c|}{1.16} & \multicolumn{2}{|c|}{4.97} \\
\hline $\mathrm{t}$-critical $(\mathrm{p}=0.95)$ & \multicolumn{8}{|c|}{1.96} \\
\hline Null hypothesis & \multicolumn{2}{|c|}{ accepted } & \multicolumn{2}{|c|}{ rejected } & \multicolumn{2}{|c|}{ accepted } & \multicolumn{2}{|c|}{ rejected } \\
\hline
\end{tabular}

The results from testing Hypothesis 1 for the US stock markets (see Tables 5 and 6) are stable for the two averaging periods (20 and 30) and confirm the presence of a statistical anomaly in the price dynamics in the US stock market after short-term overreactions.

Table 5: T-test of Hypothesis 1 for averaging period (period_dz) = 20, case of US stock market

\begin{tabular}{|l|c|c|c|c|c|c|}
\hline Type of asset & \multicolumn{2}{|c|}{ Dow-Jones index } & \multicolumn{2}{c|}{ Microsoft } & \multicolumn{2}{c|}{ Boeing Company } \\
\hline Indicator & abnormal & normal & Abnormal & normal & abnormal & normal \\
\hline Number of matches & 563 & 2610 & 341 & 1884 & 400 & 1997 \\
\hline Mean & $0.82 \%$ & $0.72 \%$ & $1.22 \%$ & $0.94 \%$ & $1.23 \%$ & $1.03 \%$ \\
\hline Standard deviation & $1.00 \%$ & $0.82 \%$ & $1.32 \%$ & $1.02 \%$ & $1.25 \%$ & $1.05 \%$ \\
\hline t-criterion & \multicolumn{2}{|c|}{2.49} & \multicolumn{7}{c|}{3.92} & \multicolumn{2}{c|}{3.18} \\
\hline t-critical (p=0.95) & \multicolumn{7}{|c|}{1.96} & rejected \\
\hline Null hypothesis & \multicolumn{7}{|c|}{ rejected } & rejected & rejed
\end{tabular}


Table 6: T-test of Hypothesis 1 for averaging period (period_dz) = 30, case of US stock market

\begin{tabular}{|l|c|c|c|c|c|c|}
\hline Type of asset & \multicolumn{2}{|c|}{ Dow-Jones index } & \multicolumn{2}{c|}{ Microsoft } & \multicolumn{2}{c|}{ Boeing Company } \\
\hline Indicator & abnormal & normal & abnormal & normal & abnormal & normal \\
\hline Number of matches & 535 & 2628 & 324 & 1890 & 371 & 2015 \\
\hline Mean & $0,87 \%$ & $0,71 \%$ & $1,20 \%$ & $0,95 \%$ & $0,58 \%$ & $0,49 \%$ \\
\hline Standard deviation & $1,06 \%$ & $0,80 \%$ & $1,32 \%$ & $1,02 \%$ & $0,59 \%$ & $0,55 \%$ \\
\hline t-criterion & \multicolumn{2}{|c|}{3,47} & \multicolumn{2}{c|}{3,44} & \multicolumn{2}{c|}{2,95} \\
\hline t-critical ( $\mathrm{p}=0.95)$ & \multicolumn{7}{|c|}{1.96} & rejected & rejected \\
\hline Null hypothesis & \multicolumn{2}{|c|}{ rejected } & \multicolumn{7}{c}{ rejed }
\end{tabular}

The results from testing Hypothesis 1 for the FOREX (see Tables 7 and 8) are not as stable as those for the US stock market. No anomaly is detected for the EURUSD (for both periods of averaging), whilst one is observed in the behaviour of GBPCHF (for both averaging periods). The USDJPY results are sensitive to the choice of the averaging period (an anomaly is found with an averaging period of 20, but not of 30).

Table 7: T-test of Hypothesis 1 for averaging period (period_dz) $=20$, case of foreign exchange market

\begin{tabular}{|l|c|c|c|c|c|c|}
\hline Type of asset & \multicolumn{2}{|c|}{ EURUSD } & \multicolumn{2}{c|}{ USDJPY } & \multicolumn{2}{c|}{ GBPCHF } \\
\hline Indicator & abnormal & normal & Abnormal & normal & abnormal & normal \\
\hline Number of matches & 534 & 2639 & 495 & 2793 & 540 & 2748 \\
\hline Mean & $0.45 \%$ & $0.48 \%$ & $0.52 \%$ & $0.48 \%$ & $0.48 \%$ & $0.44 \%$ \\
\hline Standard deviation & $0.39 \%$ & $0.41 \%$ & $0.48 \%$ & $0.45 \%$ & $0.45 \%$ & $0.46 \%$ \\
\hline t-criterion & \multicolumn{2}{|c|}{-2.07} & \multicolumn{2}{c|}{1.8} & 2.39 \\
\hline t-critical (p=0.95) & \multicolumn{7}{|c|}{1.96} & accepted & rejected \\
\hline Null hypothesis & accepted & \multicolumn{7}{|c|}{}
\end{tabular}

Table 8: T-test of Hypothesis 1 for averaging period (period_dz) $=30$, case of foreign exchange market

\begin{tabular}{|l|c|c|c|c|c|c|}
\hline Type of asset & \multicolumn{2}{|c|}{ EURUSD } & \multicolumn{2}{c|}{ USDJPY } & \multicolumn{2}{c|}{ GBPCHF } \\
\hline Indicator & abnormal & normal & Abnormal & normal & abnormal & normal \\
\hline Number of matches & 529 & 2734 & 477 & 2786 & 513 & 2765 \\
\hline Mean & $0,46 \%$ & $0,48 \%$ & $0,52 \%$ & $0,47 \%$ & $0,49 \%$ & $0,44 \%$ \\
\hline Standard deviation & $0,40 \%$ & $0,41 \%$ & $0,48 \%$ & $0,45 \%$ & $0,47 \%$ & $0,46 \%$ \\
\hline t-criterion & \multicolumn{2}{|c|}{$-0,99$} & \multicolumn{2}{c|}{2,44} & 2,57 \\
\hline t-critical $(\mathrm{p}=0.95)$ & \multicolumn{7}{|c|}{1.96} & rejected & rejected \\
\hline Null hypothesis & accepted & \multicolumn{7}{|c|}{}
\end{tabular}

Overall, it appears that in the case of $\mathrm{H} 1$ the longer the averaging period is, the bigger is the probability of anomaly detection. $\mathrm{H} 1$ cannot be rejected for the US stock 
market (in all cases) and in some cases for the FOREX (USDJPY and GBPCHF) and commodity (Oil) markets when the averaging period is 30. Therefore the classical short-term counter-movement after an overreaction day is confirmed in many cases, especially with an averaging period_dz $=30$. The only exceptions are Gold and EURUSD.

The results for $\mathrm{H} 2$ are presented in Tables 9 -13. Hypothesis 2 cannot be rejected in most cases for the commodity markets (see Table 9) (the only exception is Gold with an averaging period of 20).

Table 9: T-test of Hypothesis 2 - case of commodity markets

\begin{tabular}{|c|c|c|c|c|c|c|c|c|}
\hline $\begin{array}{l}\text { Period of averaging } \\
\text { (period_dz) }\end{array}$ & \multicolumn{4}{|c|}{20} & \multicolumn{4}{|c|}{30} \\
\hline Type of asset & \multicolumn{2}{|c|}{ Gold } & \multicolumn{2}{|c|}{ Oil } & \multicolumn{2}{|c|}{ Gold } & \multicolumn{2}{|c|}{ Oil } \\
\hline Indicator & abnormal & normal & abnormal & normal & abnormal & normal & abnormal & normal \\
\hline Number of matches & 536 & 2637 & 517 & 2656 & 538 & 2763 & 496 & 2667 \\
\hline Mean & $0,87 \%$ & $0,79 \%$ & $1,57 \%$ & $1,42 \%$ & $0,89 \%$ & $0,78 \%$ & $1,60 \%$ & $1,41 \%$ \\
\hline Standard deviation & $0,94 \%$ & $0,78 \%$ & $1,52 \%$ & $1,40 \%$ & $0,95 \%$ & $0,77 \%$ & $1,57 \%$ & $1,39 \%$ \\
\hline t-criterion & \multicolumn{2}{|c|}{1,88} & \multicolumn{2}{|c|}{2,3} & \multicolumn{2}{|c|}{2,81} & \multicolumn{2}{|c|}{2,67} \\
\hline $\mathrm{t}$-critical $(\mathrm{p}=0.95)$ & \multicolumn{8}{|c|}{1.96} \\
\hline Null hypothesis & \multicolumn{2}{|c|}{ accepted } & \multicolumn{2}{|c|}{ rejected } & \multicolumn{2}{|c|}{ rejected } & \multicolumn{2}{|c|}{ rejected } \\
\hline
\end{tabular}

The results from testing Hypothesis 2 for the US stock markets (see Tables 10 and 11) are stable for the two averaging periods (the only exception is the Dow-Jones index with an averaging period of 20) and confirm the presence of a statistical anomaly in the price dynamics in the US stock market after short-term overreactions. The same conclusion is reached for the FOREX market. In general the results for $\mathrm{H} 2$ are much more consistent (with an averaging period of 30) than the ones for H1: they provide strong evidence of an "inertia anomaly” in all markets considered after the overreaction day. 
Table 10: T-test of Hypothesis 2 for averaging period (period_dz) $=20$, case of US stock market

\begin{tabular}{|l|c|c|c|c|c|c|}
\hline Type of asset & \multicolumn{2}{|c|}{ Dow-Jones index } & \multicolumn{2}{c|}{ Microsoft } & \multicolumn{2}{c|}{ Boeing Company } \\
\hline Indicator & abnormal & normal & abnormal & normal & Abnormal & normal \\
\hline Number of matches & 563 & 2610 & 341 & 1884 & 400 & 1997 \\
\hline Mean & $0,69 \%$ & $0,65 \%$ & $1,19 \%$ & $0,98 \%$ & $1,29 \%$ & $1,07 \%$ \\
\hline Standard deviation & $0,89 \%$ & $0,83 \%$ & $1,27 \%$ & $0,94 \%$ & $1,42 \%$ & $1,12 \%$ \\
\hline t-criterion & \multicolumn{2}{|c|}{1,13} & \multicolumn{2}{c|}{3,04} & \multicolumn{2}{c|}{3,12} \\
\hline t-critical $(\mathrm{p}=0.95)$ & \multicolumn{7}{|c|}{1.96} & \multicolumn{2}{c|}{ rejected } \\
\hline Null hypothesis & \multicolumn{2}{|c|}{ accepted } & rejected & \\
\hline
\end{tabular}

Table 11: T-test of Hypothesis 2 for averaging period (period_dz) $=30$, case of US stock market

\begin{tabular}{|l|c|c|c|c|c|c|}
\hline Type of asset & \multicolumn{2}{|c|}{ Dow-Jones index } & \multicolumn{2}{c|}{ Microsoft } & \multicolumn{2}{c|}{ Boeing Company } \\
\hline Indicator & abnormal & normal & abnormal & normal & Abnormal & normal \\
\hline Number of matches & 535 & 2628 & 324 & 1890 & 370 & 2016 \\
\hline Mean & $0,75 \%$ & $0,65 \%$ & $1,27 \%$ & $1,00 \%$ & $1,95 \%$ & $1,61 \%$ \\
\hline Standard deviation & $1,05 \%$ & $0,82 \%$ & $1,34 \%$ & $0,96 \%$ & $1,50 \%$ & $1,16 \%$ \\
\hline t-criterion & \multicolumn{2}{|c|}{2,33} & \multicolumn{2}{c|}{3,62} & \multicolumn{2}{c|}{4,36} \\
\hline t-critical $(\mathrm{p}=0.95)$ & \multicolumn{7}{|c|}{1.96} & \multicolumn{2}{c|}{ rejected } \\
\hline Null hypothesis & \multicolumn{2}{|c|}{ rejected } & rejected & \\
\hline
\end{tabular}

Table 12: T-test of Hypothesis 2 for averaging period (period_dz) $=20$, case of foreign exchange market

\begin{tabular}{|l|c|c|c|c|c|c|}
\hline Type of asset & \multicolumn{2}{|c|}{ EURUSD } & \multicolumn{2}{c|}{ USDJPY } & \multicolumn{2}{c|}{ GBPCHF } \\
\hline Indicator & abnormal & normal & abnormal & normal & Abnormal & normal \\
\hline Number of matches & 534 & 2639 & 495 & 2793 & 540 & 2748 \\
\hline Mean & $0,51 \%$ & $0,45 \%$ & $0,54 \%$ & $0,48 \%$ & $0,48 \%$ & $0,43 \%$ \\
\hline Standard deviation & $0,49 \%$ & $0,41 \%$ & $0,60 \%$ & $0,49 \%$ & $0,57 \%$ & $0,41 \%$ \\
\hline t-criterion & \multicolumn{7}{|c|}{2,82} & \multicolumn{2}{c|}{2,17} & \multicolumn{2}{c|}{2,24} \\
\hline t-critical $(\mathrm{p}=0.95)$ & \multicolumn{7}{|c|}{1.96} & rejected \\
\hline Null hypothesis & \multicolumn{7}{|c|}{ rejected } & rejed & rejed \\
\hline
\end{tabular}

Table 13: T-test of Hypothesis 2 for averaging period (period_dz) $=30$, case of foreign exchange market

\begin{tabular}{|l|c|c|c|c|c|c|}
\hline Type of asset & \multicolumn{2}{|c|}{ EURUSD } & \multicolumn{2}{c|}{ USDJPY } & \multicolumn{2}{c|}{ GBPCHF } \\
\hline Indicator & abnormal & normal & abnormal & normal & abnormal & normal \\
\hline Number of matches & 529 & 2734 & 477 & 2786 & 513 & 2765 \\
\hline Mean & $0,50 \%$ & $0,44 \%$ & $0,53 \%$ & $0,47 \%$ & $0,49 \%$ & $0,43 \%$ \\
\hline Standard deviation & $0,47 \%$ & $0,41 \%$ & $0,60 \%$ & $0,48 \%$ & $0,60 \%$ & $0,40 \%$ \\
\hline t-criterion & \multicolumn{2}{|c|}{2,82} & \multicolumn{2}{c|}{2,3} & \multicolumn{2}{c|}{2,3} \\
\hline t-critical $(\mathrm{p}=0.95)$ & \multicolumn{7}{|c|}{1.96} & \multicolumn{2}{c|}{ rejected } \\
\hline Null hypothesis & \multicolumn{2}{|c|}{ rejected } & rejected & \\
\hline
\end{tabular}


Next, we analyse whether these anomalies give rise to exploitable profit opportunities. If they do not, we conclude that they do not represent evidence inconsistent with the EMH. The parameters of the trading strategies 1 and 2 are set as follows:

1. Constants

- Period_dz = 30 (explanations to this see above);

- Time_val=22 (this amounts to closing a deal after a day being in position);

- Sigma_dz=1 (see above).

2. Changeable (it needs to be optimised during testing)

- Profit_koef;

- Stop.

The results of the parameter optimisation and of the trading robot analysis are presented in Appendix D (Strategy 1) and E (Strategy 2).They imply that it is not possible to make extra profits by adopting Strategy 1 (based on Hypothesis 1) in the case of the FOREX. By contrast, there are exploitable profit opportunities in the case of the US stock market and the commodity markets; it should be noted, though, that the results are unstable and might reflect data-snooping bias in 2013 (the only exception are the very stable Wal Mart results). In general Strategy 1 (which is based on the assumption that after an overreaction day counter-movements are bigger than after a standard day) does not yield stable prpfitable results and therefore this anomaly cannot be seen as inconsistent with the EMH. Strategy 2, which is based instead on the "inertia anomaly", appears to be much more successful: it generates positive profits in the case of the Gold and FOREX (EURUSD and UDSJPY) markets, not only in 2013, but also in other time periods.

\section{Conclusions}

This paper examines short-term price overreactions in various financial markets (commodities, US stock market and FOREX). It aims to establish whether these are simply 
statistical phenomena (i.e., price dynamics after overreaction days differ statistically from those after normal days) or also represent an anomaly inconsistent with the EMH (i.e., it is possible to make extra profits exploiting them). For this purpose, first we perform t-tests to confirm/reject the presence of overreactions as a statistical phenomenon. Then we use a trading robot approach to simulate the behaviour of traders and test the profitability of two alternative strategies, one based on the classical overreaction anomaly (H1: counterreactions after overreactions differ from those after normal days), the other on a newly defined "inertia anomaly” (H2: price movements after overreactions in the same direction of the overreaction differ from those after normal days).

The findings can be summarised as follows. H1 cannot be rejected for the US stock market and in some cases for the FOREX (USDJPY and GBPCHF) and commodity (Oil) markets when the averaging period is 30 . The results for the $\mathrm{H} 2$ are even more consistent and provide strong evidence of an "inertia anomaly" in all markets considered after the overreaction day. The trading robot analysis shows that Strategy 1, which is based on the assumption that after the overreaction day counter-movements are bigger than after a standard day, is not generally profitable and therefore this anomaly cannot be seen as inconsistent with the EMH. By contrast, Strategy 2, based on the "inertia anomaly", appears to be much more successful and generates profits in the case of the Gold and FOREX (EURUSD and UDSJPY) markets. 


\section{References}

Akhigbe, A., T. Gosnell and T. Harikumar, (1998), Winners and Losers on NYSE: A Reexamination Using Daily Closing Bid-ask Spreads. Journal of Financial Research 21, 5364.

Alonso, A. and G. Rubio, (1990), Overreaction in the Spanish Equity Market. Journal of Banking and Finance 14, 469-481.

Antoniou, A., E. C. Galariotis and S. I. Spyrou, (2005), Contrarian Profits and the Overreaction Hypothesis: The Case of the Athens Stock Exchange. European Financial Management 11, 71-98.

Atkins, A.B. and E.A. Dyl, (1990), Price Reversals, Bid-Ask Spreads, and Market Efficiency. Journal of Financial and Quantitative Analysis 25, 535 - 547.

Ball, R. (2009), The Global Financial Crisis and the Efficient Market Hypothesis: What Have We Learned?. Journal of Applied Corporate Finance 21, 8-16.

Bowman, R. G. and D. Iverson, (1998), Short-run Over-reaction in the New Zealand Stock Market. Pacific-Basin Finance Journal 6, 475-491.

Brailsford, T., (1992), A Test for the Winner-loser Anomaly in the Australian Equity Market: 1958-1987. Journal of Business Finance and Accounting 19, 225-241.

Bremer, M. and R. J. Sweeney, (1991), The reversal of large stock price decreases. Journal of Finance 46, 747-754.

Bremer, M., T. Hiraki and R.J. Sweeney, (1997), Predictable patterns after large stock price changes on the Tokyo Stock Exchange. Journal of Financial and Quantitative Analysis 33, 345-365.

Brown, K. C., W.V. Harlow and S. M. Tinic, (1988), Risk Aversion, Uncertain Information, and Market Efficiency. Journal of Financial Economics 22, 355 - 385.

Chang, R., D. McLeavey and S. Rhee, (1995), Short-term Abnormal Returns of the Contrarian Strategy in the Japanese Stock Market. Journal of Business Finance and Accounting 22, 1035-1048.

Choi, H.-S. and N. Jayaraman, (2009), Is reversal of large stock-price declines caused by overreaction or information asymmetry: Evidence from stock and option markets. Journal of Future Markets 29, 348-376.

Clare, A. and S. Thomas, (1995), The Overreaction Hypothesis and the UK Stock Market. Journal of Business Finance and Accounting 22, 961-973.

Clements A., M. Drew, E. Reedman and M. Veeraraghavan, (2009), The Death of the Overreaction Anomaly? A Multifactor Explanation of Contrarian Returns. Investment Management and Financial Innovations 6, 76-85. 
Cox, D. R. and D. R. Peterson, (1994), Stock Returns Following Large One-Day Declines: Evidence on Short-Term Reversals and Longer-Term Performance. Journal of Finance 49, 255-267.

Cutler, D., J. Poterba, and L. Summers, (1991), Speculative dynamics. Review of Economics Studies 58, 529-546.

DaCosta Jr., N. C. A., (1994), Overreaction in the Brazilian Stock Market. Journal of Banking and Finance 18, 633-642.

De Bondt W. and R. Thaler, (1985), Does the Stock Market Overreact?. Journal of Finance 40, 793-808.

Fama, E. F., (1965), The Behavior of Stock-Market Prices. The Journal of Business 38, 34105.

Ferri, M., G. and C. Min, (1996), Evidence that the Stock Market Overreacts and Adjusts. The Journal of Portfolio Management 22, 71-76.

Jegadeesh, N. and S. Titman, (1993), Returns to Buying Winners and Selling Losers: Implications for Stock Market Efficiency. The Journal of Finance 48, 65-91.

Kahneman, D. and A. Tversky, (1982), The psychology of preferences. Scientific American246, 160-173.

Kothari, S. P. and J. B. Warner, (2006), The econometrics of event studies. Handbook of Empirical Corporate Finance.

Kryzanowski, L. and H. Zhang, (1992), The Contrarian Strategy Does Not Work in Canadian Markets. Journal of Financial and Quantitative Analysis 27, 383-395.

Larson, S. and J. Madura, (2003), What Drives Stock Price Behavior Following Extreme One-Day Returns. Journal of Financial Research Southern Finance Association26, 113-127.

Lehmann, B., (1990), Fads, Martingales, and Market Efficiency. Quarterly Journal of Economics 105, 1-28.

Mendenhall, W., R. J. Beaver and B. M. Beaver, (2003), Introduction to Probability and Statistics, 11th edn, Brooks / Cole, Pacific Grove.

Mynhardt, R. H. and A. Plastun, (2013), The Overreaction Hypothesis: The case of Ukrainian stock market. Corporate Ownership and Control 11, 406-423.

Poteshman, A., (2001), Underreaction, overreaction and increasing misreaction to information in the options market. Journal of Finance 56, 851-876.

Richards, A., (1997), Winner-loser Reversals in National Stock Market Indices: Can They Be Explained?. Journal of Finance 52, 2129-2144.

Stefanescu, R., D. Ramona and N. Costel, (2012), Overreaction and Underreaction on the Bucharest Stock Exchange. Proceedings of the 2nd International Conference on Business 
Administration and Economics "People. Ideas. Experience”, October 25-26, 2012, Reşiţa (22. October 2012), 367-377.

Vardar, G. and B. Okan, (2008), Short Term Overreaction Effect: Evidence on the Turkish Stock Market. Proceedings of the Conference on Emerging Economic Issues in a Globalizing World, Izmir University of Economics, 155-165.

Wang, J., B. M. Burton, and D. M. Power, (2004), Analysis of the Overreaction Effect in the Chinese Stock Market. Applied Economics Letters 11, 437-442.

Zarowin P., (1989), Does the Stock Market Overreact to Corporate Earnings Information?. The Journal of Finance 44, 1385-1399. 


\section{Appendix A}

Example of optimisation results: case of EURUSD, period 2013, H1 testing

Fig. A.1 - Distribution of results (X - profit_koef, $\mathrm{Y}$ - stop) - deeper green means better results

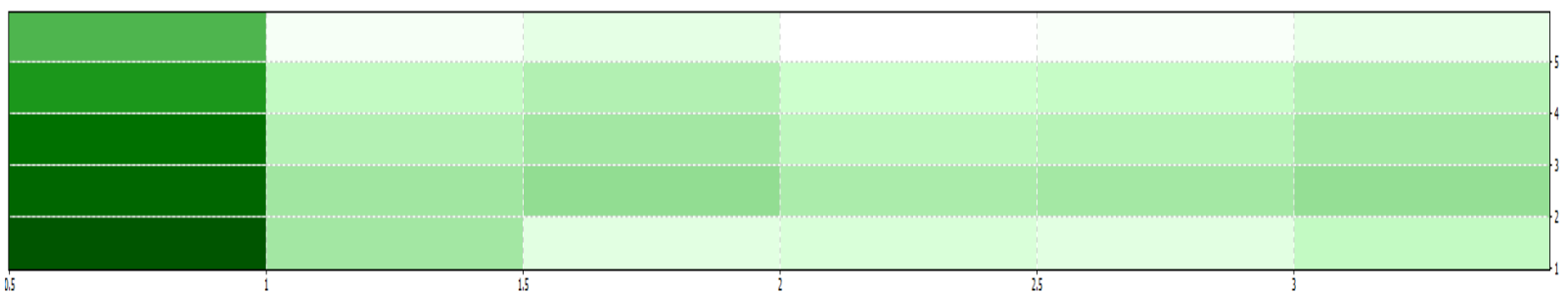

Table A.1 - Results of testing: case of EURUSD, period 2013 (changeable parameters profit_koef from 0.5 to 3 with step 0.5 ; stop from 1 to 5 with step 1 ), start deposit $=10000 \$$, size of trading lot $=$ $10000 \$$, margin (credit) leverage $=100$, time_val $=22$, period_dz=30, sigma_koef $=1$

\begin{tabular}{|r|l|r|l|l|l|l|l|l|}
\hline $\begin{array}{r}\text { Number of } \\
\text { simulation }\end{array}$ & Profit, $\$$ & $\begin{array}{c}\text { Total } \\
\text { trades }\end{array}$ & $\begin{array}{c}\text { Profit } \\
\text { factor }\end{array}$ & $\begin{array}{c}\text { Expected } \\
\text { payoff }\end{array}$ & $\begin{array}{c}\text { Drawdown, } \\
\$\end{array}$ & $\begin{array}{c}\text { Drawdown, } \\
\%\end{array}$ & Profit_koef & Stop \\
\hline 1 & -34.61 & 31 & 0.91 & -1.12 & 183.27 & $17.88 \%$ & 0.5 & 1 \\
\hline 7 & -67.61 & 28 & 0.84 & -2.41 & 170.27 & $16.90 \%$ & 0.5 & 2 \\
\hline 13 & -88.61 & 28 & 0.81 & -3.16 & 184.27 & $17.92 \%$ & 0.5 & 3 \\
\hline 19 & -168.61 & 28 & 0.69 & -6.02 & 237.71 & $23.67 \%$ & 0.5 & 4 \\
\hline 25 & -229.61 & 28 & 0.62 & -8.20 & 296.46 & $29.59 \%$ & 0.5 & 5 \\
\hline 9 & -309.61 & 28 & 0.60 & -11.06 & 330.47 & $32.98 \%$ & 1.5 & 2 \\
\hline 12 & -314.61 & 28 & 0.60 & -11.24 & 339.05 & $33.84 \%$ & 3 & 2 \\
\hline 8 & -329.61 & 28 & 0.56 & -11.77 & 413.88 & $41.31 \%$ & 1 & 2 \\
\hline 15 & -330.61 & 28 & 0.60 & -11.81 & 351.47 & $35.08 \%$ & 1.5 & 3 \\
\hline 2 & -330.61 & 30 & 0.48 & -11.02 & 414.88 & $41.41 \%$ & 1 & 1 \\
\hline 11 & -333.61 & 28 & 0.58 & -11.91 & 354.47 & $35.38 \%$ & 2.5 & 2 \\
\hline 18 & -335.61 & 28 & 0.60 & -11.99 & 356.47 & $35.58 \%$ & 3 & 3 \\
\hline 10 & -341.61 & 28 & 0.57 & -12.20 & 362.47 & $36.17 \%$ & 2 & 2 \\
\hline 21 & -348.61 & 28 & 0.59 & -12.45 & 369.47 & $36.87 \%$ & 1.5 & 4 \\
\hline 14 & -350.61 & 28 & 0.56 & -12.52 & 434.88 & $43.40 \%$ & 1 & 3 \\
\hline 24 & -353.61 & 28 & 0.59 & -12.63 & 380.15 & $37.94 \%$ & 3 & 4 \\
\hline 17 & -354.61 & 28 & 0.58 & -12.66 & 375.47 & $37.47 \%$ & 2.5 & 3 \\
\hline 16 & -362.61 & 28 & 0.57 & -12.95 & 383.47 & $38.27 \%$ & 2 & 3 \\
\hline 20 & -368.61 & 28 & 0.55 & -13.16 & 454.46 & $45.36 \%$ & 1 & 4 \\
\hline 6 & -369.61 & 30 & 0.46 & -12.32 & 431.46 & $43.06 \%$ & 3 & 1 \\
\hline 23 & -372.61 & 28 & 0.56 & -13.31 & 393.47 & $39.27 \%$ & 2.5 & 4 \\
\hline 22 & -380.61 & 28 & 0.55 & -13.59 & 401.47 & $40.07 \%$ & 2 & 4 \\
\hline 4 & -395.61 & 30 & 0.42 & -13.19 & 425.46 & $42.46 \%$ & 2 & 1 \\
\hline 5 & -405.61 & 30 & 0.41 & -13.52 & 451.46 & $45.06 \%$ & 2.5 & 1 \\
\hline 3 & -405.61 & 30 & 0.41 & -13.52 & 426.47 & $42.56 \%$ & 1.5 & 1 \\
\hline 27 & -409.61 & 28 & 0.55 & -14.63 & 430.47 & $42.96 \%$ & 1.5 & 5 \\
\hline 30 & -414.61 & 28 & 0.55 & -14.81 & 441.15 & $44.03 \%$ & 3 & 5 \\
\hline 26 & -429.61 & 28 & 0.51 & -15.34 & 515.46 & $51.44 \%$ & 1 & 5 \\
\hline 29 & -433.61 & 28 & 0.53 & -15.49 & 454.47 & $45.36 \%$ & 2.5 & 5 \\
\hline 28 & -441.61 & 28 & 0.52 & -15.77 & 462.47 & $46.15 \%$ & 2 & 5 \\
\hline & & & & & & & & \\
\hline
\end{tabular}




\section{Appendix B}

Example of strategy tester report: case of EURUSD, period 2014, H1 testing

Table B.1 - Overall statistics

\begin{tabular}{|c|c|c|c|c|c|}
\hline \multicolumn{2}{|l|}{ Symbol } & \multicolumn{4}{|c|}{ EURUSD (Euro vs US Dollar) } \\
\hline \multicolumn{2}{|l|}{ Period } & \multicolumn{4}{|c|}{1 Hour (H1) 2014.01.01 23:00 - 2014.09.26 22:00 (2014.01.01 - 2015.01.01) } \\
\hline \multicolumn{2}{|l|}{ Model } & \multicolumn{4}{|c|}{ Every tick (the most precise method based on all available least timeframes) } \\
\hline \multicolumn{2}{|l|}{ Parameters } & \multicolumn{4}{|c|}{ profit_koef $=0.5$; stop=2; sigma_koef $=1$; period_dz=30; time_val=22; } \\
\hline Barsintest & 5572 & Ticks modelled & 5138778 & Modelling quality & $90.00 \%$ \\
\hline $\begin{array}{l}\text { Mismatched charts } \\
\text { errors }\end{array}$ & 0 & & & & \\
\hline Initial deposit & 1000.00 & & & Spread & Current (2) \\
\hline Total net profit & -28.01 & Gross profit & 103.95 & Gross loss & -131.96 \\
\hline Profit factor & 0.79 & Expected payoff & -2.33 & & \\
\hline Absolute drawdown & 99.65 & Maximal drawdown & $\begin{array}{r}109.51 \\
(10.84 \%)\end{array}$ & Relative drawdown & $\begin{array}{r}10.84 \% \\
(109.51)\end{array}$ \\
\hline \multirow[t]{7}{*}{ Total trades } & 12 & Short positions (won \%) & $5(60.00 \%)$ & Long positions (won \%) & 7 (71.43\%) \\
\hline & & Profit trades (\% of total) & 8 (66.67\%) & Loss trades (\% of total) & $4(33.33 \%)$ \\
\hline & Largest & profit trade & 18.83 & loss trade & -76.14 \\
\hline & Average & profit trade & Гру.99 & loss trade & -32.99 \\
\hline & Maximum & $\begin{array}{l}\text { consecutive wins (profit } \\
\text { in money) }\end{array}$ & $5(56.71)$ & $\begin{array}{l}\text { consecutive losses (loss in } \\
\text { money) }\end{array}$ & $2(-45.65)$ \\
\hline & Maximal & $\begin{array}{l}\text { consecutive profit (count } \\
\text { of wins) }\end{array}$ & $56.71(5)$ & $\begin{array}{l}\text { consecutive loss (count of } \\
\text { losses) }\end{array}$ & $-76.14(1)$ \\
\hline & Average & consecutive wins & 3 & consecutive losses & 1 \\
\hline
\end{tabular}

Figure B.1 - Equity dynamics

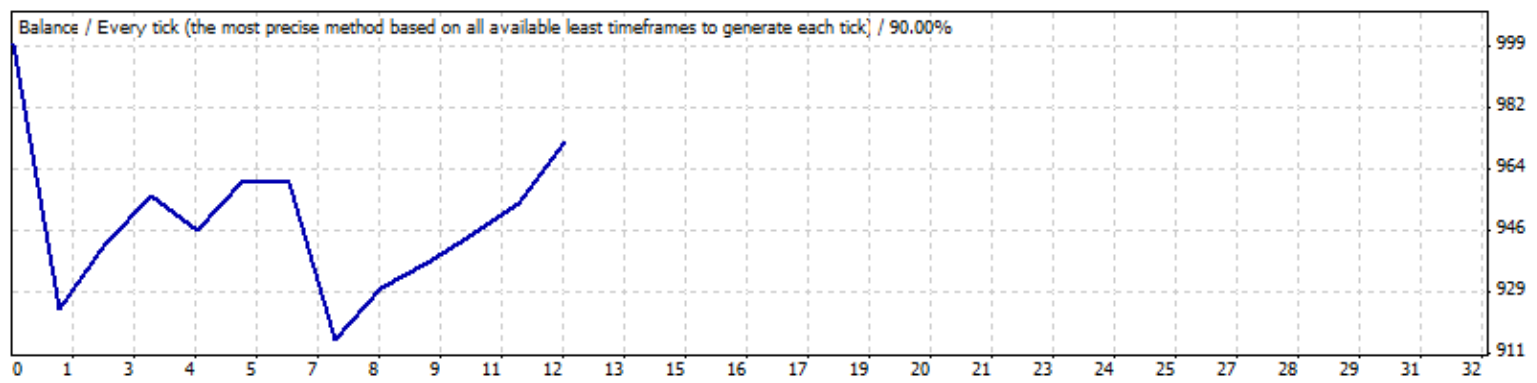


Table B.2 - Statement

\begin{tabular}{|c|c|c|c|c|c|c|c|c|c|}
\hline \# & Time & Type & Order & Size & Price & $S / L$ & $\mathrm{~T} / \mathrm{P}$ & Profit & Balance \\
\hline 1 & $02.01 .201423: 45$ & buy & 1 & 0.10 & 1.3662 & 1.3584 & 1.3681 & & \\
\hline 2 & 03.01.2014 21:45 & close & 1 & 0.10 & 1.3586 & 1.3584 & 1.3681 & -76.14 & 1.3586 \\
\hline 3 & 23.01.2014 23:00 & sell & 2 & 0.10 & 1.3696 & 1.3770 & 1.3677 & & \\
\hline 4 & 24.01.2014 9:51 & $t / p$ & 2 & 0.10 & 1.3677 & 1.3770 & 1.3677 & 18.83 & 1.3677 \\
\hline 5 & 28.02.2014 23:00 & sell & 3 & 0.10 & 1.3802 & 1.3863 & 1.3787 & & \\
\hline 6 & 03.03.2014 0:00 & close & 3 & 0.10 & 1.3788 & 1.3863 & 1.3787 & 13.83 & 1.3788 \\
\hline 7 & 06.03.2014 23:00 & sell & 4 & 0.10 & 1.3861 & 1.3924 & 1.3845 & & \\
\hline 8 & 07.03.2014 21:00 & close & 4 & 0.10 & 1.3871 & 1.3924 & 1.3845 & -10.17 & 1.3871 \\
\hline 9 & 19.03.2014 23:00 & buy & 5 & 0.10 & 1.3820 & 1.3759 & 1.3835 & & \\
\hline 10 & 20.03.2014 4:14 & $t / p$ & 5 & 0.10 & 1.3835 & 1.3759 & 1.3835 & 14.58 & 1.3835 \\
\hline 11 & 30.04.2014 23:00 & sell & 6 & 0.10 & 1.3867 & 1.3918 & 1.3854 & & \\
\hline 12 & 01.05.2014 21:00 & close & 6 & 0.10 & 1.3867 & 1.3918 & 1.3854 & -0.51 & 1.3867 \\
\hline 13 & 08.05.2014 23:00 & buy & 7 & 0.10 & 1.3841 & 1.3796 & 1.3852 & & \\
\hline 14 & 09.05.2014 13:01 & $s / 1$ & 7 & 0.10 & 1.3796 & 1.3796 & 1.3852 & -45.14 & 1.3796 \\
\hline 15 & 05.06.2014 23:00 & sell & 8 & 0.10 & 1.3660 & 1.3719 & 1.3645 & & \\
\hline 16 & 06.06.2014 10:11 & $t / p$ & 8 & 0.10 & 1.3645 & 1.3719 & 1.3645 & 14.83 & 1.3645 \\
\hline 17 & 22.07.2014 23:00 & buy & 9 & 0.10 & 1.3466 & 1.3438 & 1.3473 & & \\
\hline 18 & 23.07.2014 10:34 & $t / p$ & 9 & 0.10 & 1.3473 & 1.3438 & 1.3473 & 6.86 & 1.3473 \\
\hline 19 & 20.08.2014 23:00 & buy & 10 & 0.10 & 1.3260 & 1.3226 & 1.3269 & & \\
\hline 20 & 21.08.2014 9:30 & $t / p$ & 10 & 0.10 & 1.3269 & 1.3226 & 1.3269 & 8.58 & 1.3269 \\
\hline 21 & 04.09.2014 23:00 & buy & 11 & 0.10 & 1.2947 & 1.2913 & 1.2956 & & \\
\hline 22 & 05.09.2014 11:03 & $t / p$ & 11 & 0.10 & 1.2956 & 1.2913 & 1.2956 & 8.86 & 1.2956 \\
\hline 23 & 17.09.2014 23:00 & buy & 12 & 0.10 & 1.2874 & 1.2802 & 1.2892 & & \\
\hline 24 & 18.09.2014 11:51 & $t / p$ & 12 & 0.10 & 1.2892 & 1.2802 & 1.2892 & 17.58 & 1.2892 \\
\hline
\end{tabular}




\section{Appendix C}

Testing results for the EURUSD, period 2012-2014

Figure C.1 - Testing results for the EURUSD, period 2012-2014 (X sigma_dz, Y - time_val)*

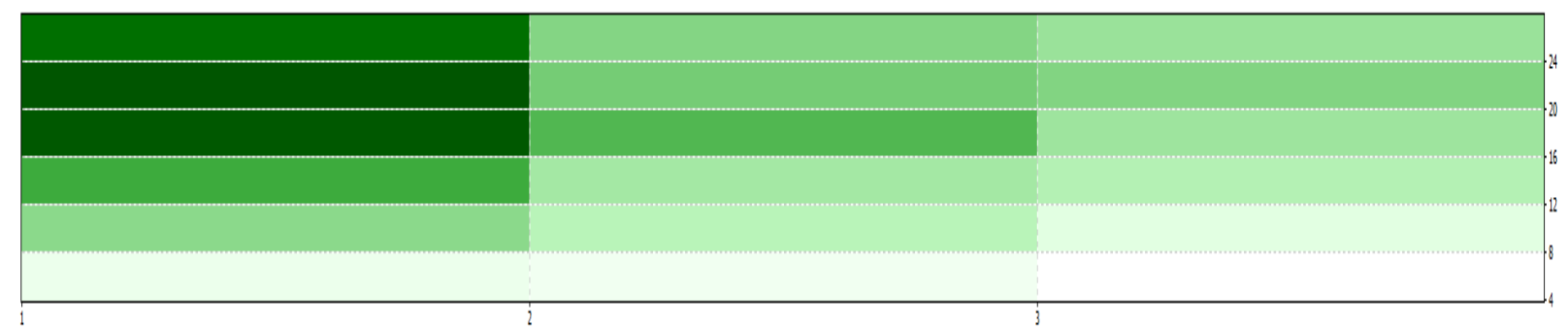

Figure C.2 - Testing results for the EURUSD, period 2012-2014 (X sigma_dz, Y - profit_koef)*

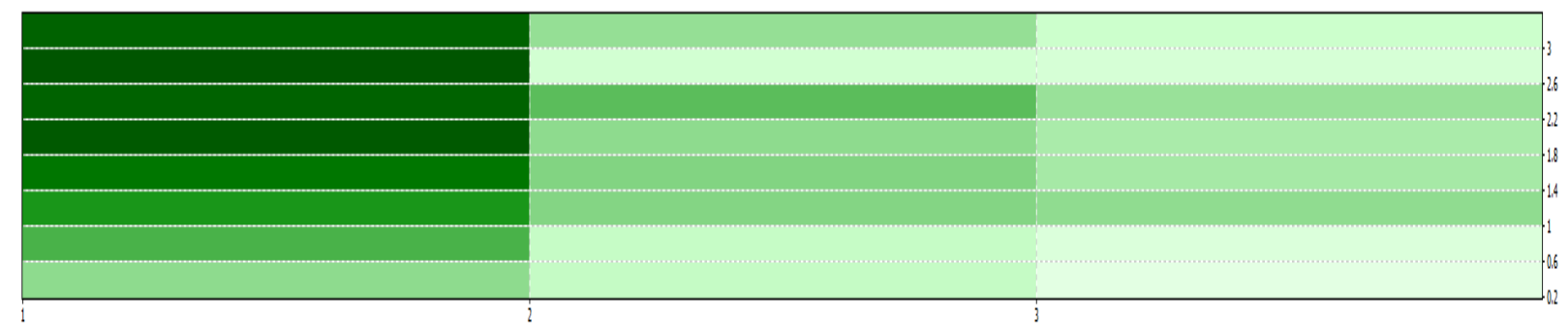

Figure C.3 - Testing results for the EURUSD, period 2012-2014 (X sigma_dz, Y - period_dz)*

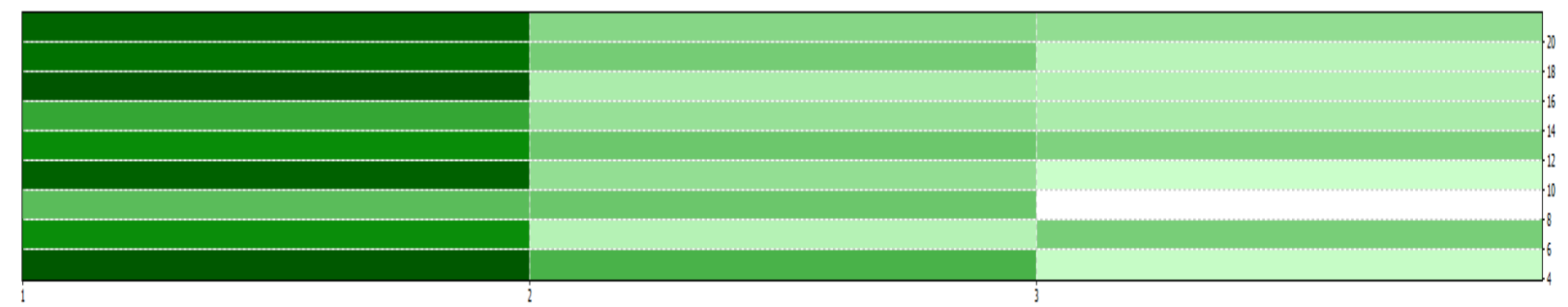

* The darker the bars, the more profitable the trading strategy is. 


\section{Appendix D}

\section{Trading results for Strategy 1}

Table D.1: Trading results for Strategy 1

\begin{tabular}{|c|c|c|c|c|c|c|c|c|c|c|c|c|c|c|}
\hline & \multicolumn{2}{|c|}{ Parameters } & \multicolumn{3}{|c|}{2012} & \multicolumn{3}{|c|}{2013} & \multicolumn{3}{|c|}{2014} & \multicolumn{3}{|c|}{ 2012-2014 } \\
\hline & $\begin{array}{l}\text { profit__ } \\
\text { koef }\end{array}$ & stop & $\begin{array}{l}\% \\
\text { succesfull }\end{array}$ & $\begin{array}{l}\text { profit, } \\
\text { USD }\end{array}$ & $\begin{array}{l}\text { annual } \\
\text { return }\end{array}$ & $\begin{array}{l}\% \\
\text { succesfull }\end{array}$ & $\begin{array}{l}\text { profit, } \\
\text { USD }\end{array}$ & $\begin{array}{l}\text { annual } \\
\text { return }\end{array}$ & $\begin{array}{l}\% \\
\text { succesfull }\end{array}$ & $\begin{array}{l}\text { profit, } \\
\text { USD }\end{array}$ & $\begin{array}{l}\text { annual } \\
\text { return }\end{array}$ & $\begin{array}{l}\% \\
\text { succesfull }\end{array}$ & $\begin{array}{l}\text { profit, } \\
\text { USD }\end{array}$ & $\begin{array}{l}\text { average } \\
\text { annual } \\
\text { return }\end{array}$ \\
\hline \multicolumn{15}{|c|}{ FOREX } \\
\hline EURUSD & 0,5 & 2 & $64,0 \%$ & -21 & $-2 \%$ & $71,0 \%$ & -67 & $-7 \%$ & $67,0 \%$ & -28 & $-3 \%$ & $68,0 \%$ & -116 & $-4 \%$ \\
\hline USDJPY & 0,5 & 5 & $70,0 \%$ & -1 & $0 \%$ & $82,0 \%$ & 225 & $23 \%$ & $69,0 \%$ & -39 & $-4 \%$ & $75,0 \%$ & 183 & $6 \%$ \\
\hline GBPCHF & 1 & 4 & $71,0 \%$ & -3 & $0 \%$ & $60,0 \%$ & -120 & $-12 \%$ & $47,0 \%$ & -207 & $-21 \%$ & $61,0 \%$ & -330 & $-11 \%$ \\
\hline AUDUSD & 3 & 1 & $23,8 \%$ & -187 & $-19 \%$ & $44,0 \%$ & 288 & $29 \%$ & $30,0 \%$ & -120 & $-12 \%$ & $32,0 \%$ & 24 & $1 \%$ \\
\hline \multicolumn{15}{|c|}{ US stock market } \\
\hline Microsoft & 1 & 2 & $63,0 \%$ & -3 & $0 \%$ & $63,0 \%$ & 8 & $1 \%$ & $55,0 \%$ & -6 & $-1 \%$ & $61,0 \%$ & 0 & $0 \%$ \\
\hline $\begin{array}{l}\text { Boeing } \\
\text { Company }\end{array}$ & 0,5 & 3 & $74,0 \%$ & -13 & $-1 \%$ & $84,0 \%$ & 56 & $6 \%$ & $80,0 \%$ & 0 & $0 \%$ & $80,0 \%$ & 44 & $1 \%$ \\
\hline Exxon & 1 & 5 & $56,0 \%$ & -30 & $-3 \%$ & $73,0 \%$ & 30 & $3 \%$ & $71,0 \%$ & 21 & $2 \%$ & $66,0 \%$ & 23 & $1 \%$ \\
\hline Wal mart & 2,5 & 1 & $37,0 \%$ & 5 & $1 \%$ & $58,0 \%$ & 50 & $5 \%$ & $50,0 \%$ & 27 & $3 \%$ & $47,0 \%$ & 82 & $3 \%$ \\
\hline \multicolumn{15}{|c|}{ Commodities } \\
\hline Gold & 3 & 5 & $43,0 \%$ & -252 & $-25 \%$ & $58,0 \%$ & 912 & $91 \%$ & $33,0 \%$ & -138 & $-14 \%$ & $51,0 \%$ & 618 & $21 \%$ \\
\hline
\end{tabular}




\section{Appendix E}

Trading results for Strategy 2

Table E.1: Trading results for Strategy 2

\begin{tabular}{|c|c|c|c|c|c|c|c|c|c|c|c|c|c|c|}
\hline \multirow[b]{2}{*}{ Financial asset } & \multicolumn{2}{|c|}{ Parameters } & \multicolumn{3}{|c|}{2012} & \multicolumn{3}{|c|}{2013} & \multicolumn{3}{|c|}{2014} & \multicolumn{3}{|c|}{ 2012-2014 } \\
\hline & profit_koef & stop & $\begin{array}{l}\% \\
\text { succesfull }\end{array}$ & $\begin{array}{l}\text { profit, } \\
\text { USD }\end{array}$ & $\begin{array}{l}\text { annual } \\
\text { return }\end{array}$ & $\begin{array}{l}\% \\
\text { succesfull }\end{array}$ & $\begin{array}{l}\text { profit, } \\
\text { USD }\end{array}$ & $\begin{array}{l}\text { annual } \\
\text { return }\end{array}$ & $\begin{array}{l}\% \\
\text { succesfull }\end{array}$ & $\begin{array}{l}\text { profit, } \\
\text { USD }\end{array}$ & $\begin{array}{l}\text { annual } \\
\text { return }\end{array}$ & $\begin{array}{l}\% \\
\text { succesfull }\end{array}$ & $\begin{array}{l}\text { profit, } \\
\text { USD }\end{array}$ & $\begin{array}{l}\text { average } \\
\text { annual } \\
\text { return }\end{array}$ \\
\hline \multicolumn{15}{|c|}{ FOREX } \\
\hline EURUSD & 0,5 & 2 & $71 \%$ & -86 & $-9 \%$ & $87 \%$ & 430 & $43 \%$ & $92 \%$ & 128 & $13 \%$ & $82 \%$ & 471 & $16 \%$ \\
\hline USDJPY & 1 & 2 & $62 \%$ & 244 & $24 \%$ & $58 \%$ & 45 & $5 \%$ & $69 \%$ & 0 & $0 \%$ & $62 \%$ & 288 & $10 \%$ \\
\hline GBPCHF & 1 & 2 & $42 \%$ & -266 & $-27 \%$ & $64 \%$ & 36 & $4 \%$ & $37 \%$ & -318 & $-32 \%$ & $51 \%$ & -560 & $-19 \%$ \\
\hline AUDUSD & 2 & 2 & $52 \%$ & 266 & $27 \%$ & $46 \%$ & -79 & $-8 \%$ & $41 \%$ & -29 & $-3 \%$ & $47 \%$ & 146 & $5 \%$ \\
\hline \multicolumn{15}{|c|}{ US stock market } \\
\hline Microsoft & 1 & 2 & $50 \%$ & -17 & $-2 \%$ & $42 \%$ & -20 & $-2 \%$ & $42 \%$ & -7 & $-1 \%$ & $45 \%$ & -46 & $-2 \%$ \\
\hline $\begin{array}{l}\text { Boeing } \\
\text { Company }\end{array}$ & 1 & 3 & $54 \%$ & -43 & $-4 \%$ & $58 \%$ & -42 & $-4 \%$ & $50 \%$ & -69 & $-7 \%$ & $51 \%$ & -150 & $-5 \%$ \\
\hline Exxon & 1 & 3 & $61 \%$ & -13 & $-1 \%$ & $60 \%$ & -40 & $-4 \%$ & $40 \%$ & -52 & $-5 \%$ & $55 \%$ & -110 & $-4 \%$ \\
\hline Wal mart & 1 & 2 & $57 \%$ & -22 & $-2 \%$ & $32 \%$ & -64 & $-6 \%$ & $47 \%$ & -25 & $-3 \%$ & $46 \%$ & -111 & $-4 \%$ \\
\hline \multicolumn{15}{|c|}{ Commodities } \\
\hline Gold & 0,5 & 5 & $64 \%$ & 22 & $2 \%$ & $73 \%$ & 608 & $61 \%$ & $100 \%$ & 276 & $28 \%$ & $75 \%$ & 903 & $30 \%$ \\
\hline
\end{tabular}

